\title{
CONSIDERACIONES GENERALES SOBRE LAS FORTIFICACIONES MILITARES EN TULUM, QUINTANA ROO, MÉXICO*
}

\author{
Ernesto Vargas Pacheco \\ Centro de Estudios Mayas \\ U.N.A.M.
}

Las fuentes históricas proporcionan valiosa información que con frecuencia puede contrastarse con los datos arqueológicos; ambos pueden complementarse y aplicarse conjuntamente al estudio de la sociedad maya, para llegar así a entender mejor, no sólo las expresiones ideológicas, sino también los restos de matcriales del pasado prehispánico. En este sentido, tanto en las fuentes históricas como en la arqueología se reflejan tales prácticas. En las primeras existen descripciones sobre armas, jefes militares, milicia, costumbres de guerra, etc. Se hace, además, frecuente referencia a los materiales que emplearon y el fin para el que construyeron murallas defensivas: de esas fuentes puedo citar la Relación de la Villa de Valladolid, Relación de Sinsimato, Bernal Díaz del Castillo, Cortés, Montejo, etc. En ellas se encuentra información de primera mano, descrita por los descubridores y conquistadores. A través de los datos proporcionados por la arqueología se puede observar la compleja y

* La información recabada por el Proyecto Tulum, que fue apoyado e impulsado por el Centro Regional del Sureste, INAH, en colaboración con el Centro de Estudios Mayas de la UNAM, me permitió la realización de este artículo, el que en parte fue presentado en el "44 Congreso Internacional de Americanistas", celebrado en Manchester, Inglaterra 1982. Agradezco el apoyo del Arqlgo. Norberto González, las sugerencias y colaboración de mis compañeras de campo Patricia Santillán S. y Marta Vilalta C., quien tuvo a su cargo la exploración y consolidación de la muralla de Tulum. También agradezco los comentarios y sugerencias de la comisión editorial del C.E.M. Dra. Mercedes de la Garza, Lic. Maricela Ayala y Lic. Ana Luisa Izquierdo. Por último, pero en primer lugar, quisiera agradecer a L. Ochoa que siempre ha estado dispuesto a corregir, discutir y esclarecer ideas. 
elaborada estructura bélica, así como el uso y perfeccionamier to de armas ofensivas y defensivas.

Múltiples ejemplos se pueden citar al hablar de fortificaciones: en Guatemala encontramos las fortalezas de los quichés, cakchiqueles y mames; en Chiapas existen evidencias en las tierras altas; para Campeche basta citar las albarradas de Champotón y el foso de Becán. En Yucatán y Quintana Roo se encuentran entre otros, sitios amurallados en Cuca, Chacchob, Mayapán, Chichén Itzá, Tulum, Xcaret, Playa del Carmen, Ichpaatun, etc.

Consideramos de importancia centrar en este estudio los sitios amurallados que se localizan en Quintana Roo, con el propósito de plantear algunos comentarios, debido al interés que revisten en el estudio de la evolución cultural, basándonos fundamentalmente en la información obtenida en las últimas exploraciones realizadas en Tulum y enmarcándolo dentro del modelo sociocultural desarrollado por Piña Chan (1976). El objetivo primordial que se pretende señalar aquí es el de analizar los materiales de acuerdo con dicho marco de referencia para tratar un tópico de gran interés para el ámbito mesoamericano y muy en particular, para la zona maya. Noticias de la existencia de las obras fortificadas en el área maya, son de antiguo conocidas. Stephens (1848), al referirse sobre la muralla de Tulum, comenta que en casi todos los sitios que había visitado le hablaron de murallas y la única que había visitado era precisamente ésa.

Actualmente de acuerdo con las últimas investigaciones realizadas en este sitio estamos en posibilidad de saber cuándo se construyó la muralla; también podemos saber en términos generales sus etapas y sistema constructivo. Y por medio de los levantamientos topográficos, el estudio preliminar del patrón de asentamiento y los resultados de las excavaciones efectuadas tendremos mayores posibilidades de entender la planeación y orientación militarista de Tulum.

Ahora bien, el problema con el cual nos enfrentamos es llegar a dilucidar las causas que condujeron a la necesidad, no sólo para los habitantes de Tulum en particular sino los del área maya en general, de concebir y erigir tales construcciones; puesto que la inversión energética tenía que ser redituable en términos económicos y/o políticos. Así, durante el Postclásico (1000-1500 D.C.) centros como Tulum, Ichpaatun, Xcaret, Mayapán, Iximché, Mixco Viejo, etc., indican que tuvieron que invertir una gran cantidad de esfuerzo en tales construcciones.

Para el periodo Clásico Tardío evidencias indirectas se pueden 
observar en representaciones de escenas de batallas, prisioneros, comerciantes que viajan con escolta de guerreros y uso de armas, como son los casos de las pinturas murales de Bonampak y Mul Chic, en estelas y dinteles de Piedras Negras, Bonampak, Yaxchilán, La Mar, Seibal Balancán, etc.

De épocas anteriores, como el Clásico Temprano, aunque hay menos evidencias, ya existe un cierto énfasis guerrero que conduciría posteriormente a la posible integración de organizaciones militares más fuertes. Sin embargo, nada de ello es factible obtener o aceptar para el Preclásico, aunque la ausencia de tales datos no significa necesariamente la inexistencia de guerras.

Los trabajos realizados por Webster (1976) en Becán, al sur de Campeche, revelan que el foso se edificó, según sus apreciaciones a fines del Preclásico cuando la civilzación maya aún estaba en sus etapas formativas. De este periodo definitivamente no nos ocuparemos, tampoco de aquellas construcciones de materiales perecederos dado que no se conservan indicios como son las palizadas, enramadas, etc. Otras en cambio pueden tener más de una función, por lo tanto se necesita un examen más detallado para definir la función principal o funciones que tuvieron.

Las evidencias arqueológicas parecen indicar que algunos centros y ciudades teocráticas inician el militarismo y se desarrollan con un incremento en la densidad de la población, con una marcada complejidad social, fuerte división de trabajo, comercio intensivo y concentración de excedentes económicos, entre otras características. Así se forman grupos privilegiados que detentan el poder y la riqueza (nobles, sacerdotes, comerciantes, artesanos, etc.), con base en un sistema social jerarquizado y con un jefe teocrático o señor; además de las relaciones entre centros y urbes, se sientan las bases para el desarrollo de la escritura, las artes, conocimientos artronómicos, etc.

Posteriormente derivan a etapas donde un grupo de individuos ajenos a la producción de alimentos, se impone a otros grupos por medio de la fuerza, y con ello surgen los tributos obligatorios, cuerpos represivos, centros fortificados, y fabricación de armas, etc., que conduce al Estado Militarista en diversos grados.

El origen del Estado es uno de los problemas más difíciles a que nos hemos enfrentado en el estudio de la evolución y desarrollo de las sociedades. Entre otros Carneiro (1970) y Service (1975) han hecho aportaciones valiosas a tal asunto. El primero define al Estado como una unidad política, autónoma que abarca muchas co- 
munidades dentro de su territorio, con un gobierno centralizado con el poder de colectar impuestos, reclutar hombres para el trabajo o la guerra, decretar y ejecutar leyes. Esta centralización del poder la explica de dos maneras: una en donde sostiene que las gentes se unen de manera espontánea, racional y voluntariamente para formar una unidad política, y la otra en donde la fuerza y no los propios intereses los encauzó poco a poco a la unión de aldeas autónomas hasta convertirlas en Estados.

Service (1975:14-16) nos dice que el Estado es el único que puede respaldar los requerimientos de la sociedad por la fuerza más que por la sola opinión pública o alguna otra forma de acción personal independiente y se diferencia de la sociedad primitiva por el hecho de que ley y gobierno están institucionalizados, promulgados y autorizados amén de que emplean o implican el uso real de la fuerza.

Para el estudio de las complejas culturas mesoamericanas se han desarrollado diferentes modelos; no contemplo realizar aquí un análisis crítico de dichas aportaciones, solamente trataré de presentar un somero análisis de un determinado tipo de sociedades que se dio en Mesoamérica y en la zona maya; las sociedades militaristas. Antes de pasar a desarrollar estas ideas generales quiero hacer notar, como dije anteriormente, que ésta es una característica de la humanidad, sin olvidar que este modelo se aplica claramente para las sociedades tardías. $\quad$ i

Nos basamos en el modelo de evolución social y cultural del México precolombino presentado por Piña Chan (1976). Es importante advertir que pongo énfasis en el aspecto militarista y que los diferentes aspectos de vida ya sean del tipo de recolectores-cazadores, etc., pudieron existir hasta los tiempos de la conquista española y lo mismo aconteció con las aldeas, centros y ciudades.

Como se mencionó anteriormente existen ya algunos modelos propuestos para comprender el desarrollo sociocultural de Mesoamérica, pero el presentado por Piña Chán nos sirve como marco apropiado para ordenar sistemáticamente y coherentemente las evidencias arqueológicas y los hechos históricos, posiblemente sea necesario formularlo con términos más claros y precisos que muestren dicha evolución y cambios. Al contrastar estos modelos de desarrollo con estudios específicos nos conducirán sin duda al enriquecimiento del instrumental teórico que vendría a cubrir un vacío muy importante.

Guando Piña Chán presentó su modelo para una revisión crítica, lo expuso de la siguiente forma: 
I. EPOCA DE APROPIACIÓN DE ALIMENTOS. ETAPA DE LOS RECOLECTORES Y GAZADORES NOMA. DAS.

Periodo Preagrícola: $\quad 20000$ - 7000 a.C.

Periodo Protoagrícola: $\quad 7000$ - 5000 a.C.

II. EPOCA DE LA PRODUCCIÓN DE ALIMENTOS. ETAPA DE LAS COMUNIDADES SEDENTARIAS.

Periodo Agrícola Incipiente: $\quad 5000$ - 2400 a.C.

Periodo Agrícola Aldeano 2400 - 1200 a.C.

ETAPA DE LOS PUEBLOS Y ESTADOS TEOCRÁTICOS

Periodo de las Aldeas y Centros Ceremoniales.

1200 a.C. - 200 d.C.

Periodo de los Centros Ceremoniales y Ciudades

200 d.C. - 900 d.C.

ETAPA DE LOS PUEBLOS Y ESTADOS MILITARISTAS

Periodo de las Ciudades y Señoríos Militaristas:

900 d.C. - 1250 d.C .

Periodo de los Señoríos y Metrópolis Imperialistas:

1250 d.C. - 1521 d.C.

Como expuse, me ocuparé de rastrear la importancia del papel jugado por el aspecto militar en cualquiera de sus etapas, ya que no tenemos conocimiento de cuándo se inició la institución de la guerra en la zona maya, ni cuáles fueron sus repercusiones. Los restos arqueológicos al respecto son muy difíciles de documentar y algunos son susceptibles de interpretaciones múltiples. Las evidencias al respecto se inician desde el Periodo de los Centros Ceremoniales y Ciudades, y aún desde el periodo anterior, correspondiendo a un desarrollo sociocultural que encuadraría dentro del modelo que venimos tratando y desarrollaremos con mayor detalle a continuación.

Puesto que no tenemos ninguna evidencia arqueológica disponible para el momento que corresponda a la Etapa de las comunidades sedentarias (5000-1200 a.C.), comenzaré por el Periodo de los Centros Ceremoniales y Ciudades (200-900 d.C.), sobre todo porque hacia los finales de ese periodo comienza a mostrarse cierto énfasis guerrero que conducirá claramente a la integración de los Estados Militaristas, aunque como dije, ya desde antes existen algunas evidencias de militarismo.

En términos generales ese periodo se puede caracterizar por una economía que produce suficientes excedentes para el sostenimiento de una creciente población no productora de alimentos, concentrada 
en centros mayores, tendientes en varios casos al urbanismo, éstos se piensa que estuvieron regidos por jefes-sacerdotes principales, los cuales constituyen un gobierno central, organizador de las obras públicas, de las manufacturas, del comercio, de la administración y de la política.

Los excedentes económicos se obtienen por la tributación de algunas aldeas, por la producción artesanal más especializada y por el comercio intensivo que incorpora materias primas, objetos y recursos de otras regiones, todo ello era tributado en forma voluntaria o por el respaldo de una fuerza represiva, lo cual permite el sostenimiento de los grupos no productores de alimentos.

En la región maya florecieron centros como Palenque, Bonampak, Yaxchilán, Piedras Negras, Tikal, Kaminaljuyú y muchos más; casi todos estos centros eran sostenidos por aldeas y pueblos vecinos, ejerciendo el control sobre un territorio determinado; lo que nos indica que varios centros y ciudades teocráticas están respaldados por un aparato militar ya desde esta etapa.

La Etapa de los Pueblos y Estados militaristas marca un momento importante en el desarrollo sociocultural en Mesoamérica; sin embargo, después del año 800 muchos de los pueblos teocráticos mayas de las tierras centrales entran en la decadencia debido a varios factores hasta ahora no bien definidos, pero que pueden sintetizarse de la siguiente forma:

"Las causas que llevaron a los mayas a ese desequilibrio y más tarde a su decadencia cultural siempre ha sido objeto de discusión; a pesar de ello, las explicaciones casi siempre se han apoyado en un hecho aislado, y pocas veces se ha tratado de ver que, si bien uno pudo haber sido el primero, no necesariamente tuvo que haber sido el único, pues todo tiende a indicar que fue la concatenación de varias causas lo que ocasionó el colapso. En este sentido, como dijéramos antes, no vamos a entrar al análisis pormenorizado de este fenómeno, pero si pensamos que las causas relacionadas con la decadencia pueden considerarse como de carácter interno y externo; de índole natural, sociopolítica y económica; pero también creemos que ni unas ni otras, en forma aislada, son suficientes para explicar racionalmente este suceso". (Cuadro) (Ochoa y Vargas, 1979:64 y 65).

El colapso maya no se puede explicar aisladamente, son muchos los factores que intervienen en ese fenómeno, y las guerras internas y externas al parecer jugaron un papel importante en la desintegración del mundo clásico. 


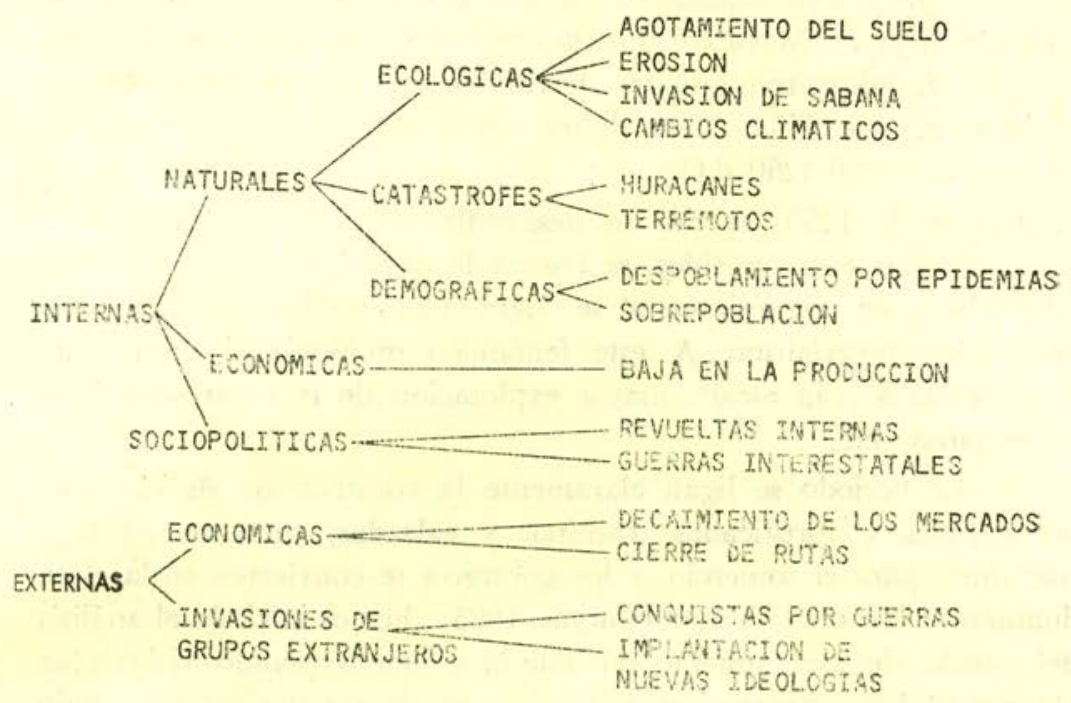

Jiménez Moreno, al referirse a este periodo final del Horizonte Clásico, nos dice:

"Una gran crisis sacude a Mesoamérica del uno al otro confín y en medio del caos se incuba un mundo nuevo. Hay un cambio profundo, de orientación cultural, en el que naufragan las viejas culturas milenarias y dominan las gentes que proceden de áreas periféricas o rezagadas. Como la situación imperante tuvo que ser inestable - pues ocurre así cuando se uperan transiciones bruscas- el panorama se vuelve borroso y confuso a los ojos del historiador que trata inútilmente de lograr una imagen bien afocada de lo que sucedió entonces." (Jiménez M., 1976:1064).

Las fuentes históricas para esta etapa ya empiezan a tener gran importancia, en ellas se narra la movilidad o migración de algunos grupos (toltecas, olmecas-xicalancas, nonoalcas, itzáes, xiues, quichés, etc.), aparecen nuevos linajes y algunos pueblos se nombran herederos de ciertas tradiciones; se forman pueblos o sociedades que sojuzgan por la fuerza a otras poblaciones y se integran centros rectores más ampilos.

En la región maya y especialmente en la Península de Yucatán, se observa cómo los xiues ocupan Uxmal y los itzáes Chichén Itzá. 
De esta manera, las ciudades se van rodeando de un muro defensivo, a manera de ciudades fortificadas; o bien se establecen alianzas como la Liga de Mayapán. Los guerreros se convierten en la clase dominante, adquieren grandes territorios por conquistas; este periodo es el que Piña Chán define como de Ciudades y Señoríos Militaristas (900-1250 d.C.).

Después de 1250 , se da un desarrollo claro del militarismo, se crean alianzas entre pueblos, se ensaya la organización política confederada y en algunos casos se logra una unidad política, con tendencias imperialistas. A este fenómeno se asocia el urbanismo, el comercio a gran escala, mayor explotación de recursos materiales y humanos, etc.

A este periodo se ligan claramente la construcción de ciudades amuralladas y fortificadas, caminos y calzadas, rutas terrestres y marítimas para el comercio, y los guerreros se convierten en la clase dominante. En otro trabajo (Vargas, 1983), hemos iniciado el análisis del patrón de asentamiento en Tulum y hemos podido vislumbrar algunas de las características que hemos señalado anteriormente; todo ello nos ayudará a entender mejor a Tulum, que es uno de los mejores ejemplos para estudiar el militarismo, aunque presenta serios problemas para enmarcarlo dentro de este tipo de desarrollo sociocultural.

No sólo Tulum, sino también lugares como Mayapán, Izamal y otros centros, revelan esa situación; los cocomes, xiúes, cheles, itzáes, peches, canules, etc., reinan y gobiernan sobre provincias constituidas por aldeas, pueblos y pequeños centros ceremoniales; se mantiene el control sobre los recursos materiales de esos amplios territorios por las armas. Todo ello tal vez explicaría por qué a la llegada de los españoles el territorio de la península de Yucatán estaba dividido en provincias. Roys (1957) nos dice que en tiempos cercanos a la conquista la península de Yucatán quedó dividida en 19 cacicazgos, de los cuales tres, por lo menos, quedaron dentro del territorio del Estado de Quintana Roo, a saber: los cacicazgos de Ecab, Cochuah y Chetumal.

Tulum es uno de los principales sitios de la provincia de Ecab y estaba en los límites meridionales, fronterizo con la provincia de Cochuah; tal vez fue por eso que Tulum estaba amurallada, ya que era un puesto defensivo para impedir las incursiones de grupos enemigos, reflejándose así la situación reinante durante el Postclásico Tardío. 


\section{Fortificaciones en Yucatān}

En Yucatán se encuentran algunos sitios fortificados tales como: Mayapán, Chichén Itzá, Uxmal, Cacchob, Dzonot Aké, Muna, Aké y Chunchucmil, entre otros. El estudio de ellos nos proporciona una útil perspectiva para compararlos con los de Quintana Roo ya que presentan características que nos brindan valiosa información sobre los pueblos que los construyeron.

Ahora bien en este tipo de fortificaciones existen algunas diferencias; en Chichén Itzá, por ejemplo, tenía una muralla que abarcaba solamente al grupo principal de edificios: el juego de pelota, el castillo, el tzompantli, la plataforma de las águilas, el templo de los guerreros y el grupo de las mil columnas (Ruz L., 1952: 331-342).

Dicho autor opina que la muralla de Chichén Itzá fue menos ancha que la de Mayapán, pero aproximadamente de la misma altura: 2 metros; aunque su sistema de construcción fue como el de Mayapán, Tulum y Xelhá, es decir piedras labradas tanto en el interior como en el exterior. Actualmente con las exploraciones realizadas en el interior de la muralla de Tulum, podemos describir con mayor detalle el sistema de construcción en dicho sitio, pues, al parecer, dentro de la misma muralla existen por lo menos dos sistemas de construción diferentes, que describiremos posteriormente.

Por otra parte, en los sitios de Muna, Cuca y Aké la mayoría de los edificios principales quedaron dentro del área amurallada, solamente algunas plataformas grandes y bajas están situadas fuera de ella, si bien existe la posibilidad de que no se hubiera localizado el resto de las construcciones a causa de la vegetación que impide verlas.

Kurjack y Andrews (1976: 317-325) apuntan que los muros de Cuca parecen haber sido construidos colocando apoyos de lajas de piedra caliza de unos 35 a $50 \mathrm{cms}$. de espesor y unos $50 \mathrm{cms}$. o más de altura, como base de dos muros paralelos, a junta seca, separados entre sí por 1.50 a $2 \mathrm{mts}$. El espacio que queda entre ellos se rellenó con fragmentos de piedra caliza. Hay suficientes vestigios in situ que indican que los muros pudieron haber tenido de 1.50 a 2 metros de altura.

Chunchucmil (Kurjack 1977) también está rodeado por una muralla que no pudo haber alcanzado una altura mayor de un metro, su ancho promedio parece tener esa misma dimensión y el sistema de construcción consistió en dos hiladas de grandes piedras, para- 
lelas, y un núcleo de piedras menudas para rellenar el espacio comprendido entre las dos hiladas.

No obstante el hecho de encontrarse fuera de nuestra área geográfica de estudio merece especial atención al sistema defensivo utilizado en Becán, Campeche. Los arquitectos que planearon y construyeron este sitio hicieron una gran zanja de forma arriñonada que envuelve completamente al centro ceremonial, el relleno que se removió se apiló a lo largo del borde interior, lográndose, de ese modo, unos metros más de altura; además los pantanos que rodean al sitio hacen difícil su acceso.

Webster (1972:34-37) dice que Ruppert y Denison nombran e identifican las características básicas del sistema defensivo de Becán al mencionar las zanjas, el parapeto y los sacbes. $\mathrm{Al}$ respecto Thompson (1959:119) dice que Becán es una contraprueba sobre la idea de que la guerra en gran escala y las fortificaciones se deben a la influencia mexicana. Hay que desechar, como algunos autores apun$\tan$, la tesis de que la sociedad maya vivió en paz, dedicada a los logros científicos y artísticos, manteniéndose al margen de los conflictos sociales y de la guerra, y que durante el Postclásico se dio un cambio brusco con la llegada de grupos mexicanos. Durante el desarrollo de este artículo puede verse claramente que existe, en diferentes grados, la presencia de elementos, que señalan el carácter militarista de esta sociedad durante casi todos los periodos; la situación es compleja y es importante señalarla.

\section{Fortificaciones en Quintana Roo}

Para la costa de Quintana Roo también se han reportado varios sitios amurallados, ya sea total o parcialmente: Xcaret, Playa del Carmen, Xelhá, Tulum e Ichpaatun entre otros.

\section{Xcaret}

La muralla que rodea a Xcaret consiste en un muro que corre paralelo a la costa y limita la parte sur de la pequeña caleta, que dando protegidos los grupos A, B y C (Andrews y Andrews 1975).

"La muralla de Xcaret indudablemente sirvió como muralla decorativa y/o con propósitos ceremoniales. En cuanto que no protege 
al sitio ni desde dentro ni desde la costa, no pudo haber tenido una función militarista. El sitio está bien defendido por el lado del mar por una costa rocosa. El único medio de acceso al sitio desde el mar es a través de la angosta caleta. Un pequeño grupo de hombres puestos en ambos lados de la boca de la caleta, pueden fácilmente asegurar su defensa de intrusos marítimos indeseables." (Andrews y Andrews 1975:36).

Originalmente, la muralla debió tener una altura de 1.5 a 2 metros de altura; Mason reporta que la muralla era de 6 pies de alto cuando visita el sitio en 1926.

El sitio arqueológico, como queda descrito en la cita anterior, estaba bastante bien resguardado por la angosta caleta que podía ser fácilmente defendida y por la costa rocosa que dificultaba el acceso. La muralla, además, se ubica hacia la pequeña caleta como si sirviera de defensa contra atacantes que vinieran del mar. No dudamos que la muralla tuviera fines decorativos y propósitos ceremoniales, pero no descartamos la posibilidad de que tuviera también una función militarista (Fig. 1).

\section{Playa del Carmen}

Recientemente en Playa del Carmen se realizaron trabajos que, además de consolidar y restaurar varios de los edificios allí existentes, exploraron una muralla que rodea uno de los grupos principales; es interesante señalar que esta muralla es relativamente baja, aurıque al parecer pudo haber tenido más altura, sin embargo circunda varias estructuras, que bien pudieron constituir el grupos más importante.

"murallas": sólo pudimos detectar la presencia de un elemento de este tipo. Uno de sus extremos se localiza unos pocos metros al sur de la estructura C IV y el otro se encuentra al sur del Grupo B podemos decir que delimitaba al grupo $\mathrm{C}$ por el occidente y aunque sus extremos han sido destruidos casi totalmente, suponemos que llegaba hasta la playa por los restos que aún se conservan (González de la Mata y Trejo F., 1981:129).

En el proyecto Playa del Carmen todavía se están realizando los estudios de gabinete; cuentan además con planos topográficos del sitio, y seguramente la información que saldrá cuando se publiquen los estudios finales dará una idea más clara de la función de dicha muralla y del sitio en generai. 


\section{Xelhá}

Casi todos los investigadores que han trabajado la Costa Oriental de Quintana Roo visitaron el sitio; en los últimos años el Centro Regional del Sureste ha venido realizando trabajos de investigación que incluyen levantamientos topográficos y excavaciones, cuyos resultados constituyen importantes aportaciones para entender mejor el desarrollo cultural del sitio y de la región. Por medio de las excavaciones se ha podido constatar que la mayor ocupación corresponde al Clásico, aunque sus restos más antiguos vienen desde el Preclásico y llegan hasta el Postclásico. Para el tema que venimos desarrollando sólo nos interesa lo más tardío, ya que la muralla y algunos edificios son del Postclásico (Robles, 1981), sin embargo la descripción hecha por Lothrop de la muralla sigue siendo válida (Fig. 2).

"En la bifurcación de los 2 brazos de la bahía de Xelhá hay una península de aproximadamente 200 yardas tanto de largo como de ancho, que se junta con la tierra firme por una estrecha porción de tierra, que está defendida por una muralla de piedra, estructuralmente comparable a la gran muralla de Tulum. Tiene una altura promedio de 8 a 25 pies.

"La parte sur de la muralla termina abruptamente al borde de un pequeño acantilado sobre el mar, que en esta parte es bastante profundo. Un poco más al oeste hay una pequeña isla a la que se llega por un puente formado por una gran losa de piedra caliza. La única entrada hacia la península se encuentra cerca del extremo sur de la muralla, es un pasadizo estrecho que da vuelta en ángulo recto. $\mathrm{Al}$ norte de la entrada la muralla es mucho más ancha que antes y tiene un parapeto bien definido en la parte exterior. A 35 pies de la entrada hay una curva en la parte exterior similar a las que se encuentran en el brazo sur de la muralla de Tulum, y que proporcionan una situación privilegiada para fuego cruzado. En esta esquina hay un pequeño cuarto construido en el grosor del parapeto, probablemente para guardar armas. 40 pies al norte de la curva, la muralla alcanza el agua en el otro lado de la península, no termina allí sino que se prolonga a 60 pies sobre la orilla. La razón aparente de esto es que el agua no es aquí tan profunda como en el extremo sur, y la extensión a lo largo de la orilla es necesaria para prevenir que los atacantes caminaran por el agua poco profunda, bordeando la muralla" (Lothrop, 1924: 134).

Cabe resaltar la situación estratégica de esta muralla, el acceso a la caleta es de fácil protección y en caso de querer entrar, el único sitio para desembarcar sería el lugar en donde se encuentra 
la muralla, ya que el asentamiento prehispánico se localiza tierra adentro intercomunicando los principales grupos por medio de sacbés. La muralla fue, sin lugar a duda, construida para protegerse de posibles enemigos que pudieran llegar por el mar. Es importante este hecho porque en algunos sitios se protegen las entradas por mar y en otros, al parecer, son defendidos de posibles ataques provenientes de tierra adentro.

\section{Tulum}

Enclavado frente al mar tiene una muralla en su frente terrestre que circunda la población por tres de sus lados y en una distancia aproximadamente de $700 \mathrm{mts}$. Su frente al mar está protegido por los acantilados. Los muros son de 3 a $7 \mathrm{mts}$. de alto, y aún hasta $9 \mathrm{mts}$. en su parte exterior. El grosor también es variable de 3 a 6 mts. Estos muros se conservan mejor que los de Mayapán y fueron construidos posiblemente con propósitos militares. En una de las cinco puertas el pasadizo que tiene es tan angosto que apenas llega a $1.20 \mathrm{mts}$. de ancho, de modo que el invasor tenía que entrar al pasillo y al pasar podía fácilmente ser atacado, además estas entradas servían seguramente para controlar el paso de las personas que visitaban y llegaban a Tulum (Lámina 1).

Algunos autores, no ven muy clara la función defensiva de la muralla; establecen, por ejemplo, que la muralla termina un poco antes de llegar al acantilado, facilitando el paso por ambos flancos, durante posibles ataques, hacia el interior de la ciudad. También impugnan que la muralla si bien es muy maciza, no es demasiado alta y no impide trepar por ella con mucha facilidad.

La mayoría de los edificios de mampostería se encuentra en el interior de la muralla, por lo tanto piensan que la muralla podría ser una representación simbólica que marcara la frontera del recinto sagrado diferenciándolo del área suburbana que ocuparía las afueras de la ciudad (Andrews G., 1975).

La situación de las casas habitación de Tulum es muy similar a la de Mayapán en cuanto a la abundancia de albarradas, espacios cercados; pero en Mayapán la mayoría está en el interior de la muralla, lo que tal vez se deba a que los gobernantes para mantener un estrecho control sobre la península obligaran a los jefes principales a residir en Mayapán, mientras que en Tulum el grueso de ia población viviría fuera de las murallas. 
Al igual que Mayapán, Tulum también tiene una segunda muralla, más pequeña, que circunda un espacio rectangular; posiblemente en el caso de Tulum esta segunda muralla no tuvo ningún sentido militar, sino que haya sido un recinto protegido en donde se limitaría la entrada a la gente común (Lámina 2); con las exploraciones que hemos realizado puede constatarse la construcción de ciertas paredes para cerrar los espacios libres, mientras que la muralla exterior seguramente tuvo doble finalidad: una eminentemente defensiva y otra para el control de la gente que entraba a la ciudad; pues a cada una de las puertas de la muralla llegaba un sacbé, y además existía un reforzamiento de vigilancia. En el lado norte, en la primera puerta, había un pequeño cuarto en donde al parecer podían estar los vigilantes (Lámina 3); en la segunda puerta, fuera de la muralla había dos grandes plataformas que servían para vigilar la entrada y salida, y sobre la muralla una especie de parapeto que protegía a los vigilantes.

Con las exploraciones que venimos realizando en Tulum hemos podido obtener una gian cantidad de información, no sólo con respecto a la muralla sin ı también a la planeación de la misma; en trabajos posteriores analizaremos más profundamente este aspecto, porque creemos que es básico para entender el desarrollo sociocultural que se da en un sitio o en una región.

Como resultados preliminares de los trabajos realizados en la muralla de Tulum, se ha visto que se compone de 2 ó 3 cuerpos y se han hallado, sólo en el lado norte, 9 accesos o escaleras que daban a la parte superior (Lámina 4); también allí se limpió un pequeño cuarto adyacente a la puerta noreste.

En esta puerta noreste se limpiaron y consolidaron escaleras que daban hacia la parte superior y allí se exploró un parapeto que servía seguramente para proteger a los vigías que custodiaban las entradas y salidas.

Con la información obtenida durante nuestras exploraciones, como señalé anteriormente se localizaron escaleras y detalles arquitectóni$\cos$ de la muralla que nos permiten inferir aspectos sobre la forma en que fue planeada dicha muralla para defender el sitio en caso de ataque.

Hacia el lado norte, al parecer no tuvieron que reforzarse, les bastó con la muralla que cierra los principales edificios; sin embargo hacia el sur construyeron otra muralla que sale de la esquina suroeste y protege gran parte de la zona habitacional (Fig. $3)$. Todo esto nos indica que la situación reinante en Tulum era 
bastante insegura o que se tomaron medidas preventivas de gran alcance, ya que la construcción de dichas murallas necesitaba un gran esfuerzo humano, dada la magnitud de la obra, así como la escasez de recursos tecnológicos.

Estos muros son de diferentes dimensiones, colocados de tal manera que oponían al enemigo un obstáculo insuperable. Son construcciones de una forma muy sencilla, sin adornos de ninguna clase, siendo a veces sumamente toscas; rodeaban por completo la ciudad o al menos su núcleo más importante. Estaban casi privadas de aberturas, excluyendo, como es lógico, las puertas de entrada. En la parte superior, las murallas solían estar dotadas de pasillos que permitían a los soldados efectuar guardias constantes y que en caso de ataque ofrecían una posición de ventaja frente al enemigo.

Se trata de construcciones defensivas inventadas por el hombre para salvar no sólo vidas humanas, sino también viviendas y bienes. Las fortificaciones son un elemento importante en la defensa ya que entre otras cosas sirve para prevenir sorpresas, proteger a los que combaten, brindar seguridad a la población que vivía afuera y facilitar maniobras de las tropas que peleaban extramuros.

\section{Ichpaatun}

Es otro sitio arqueológico amurallado de la costa oriental, al parecer está casi totalmente destruido. Escalona y Ramos (1946: 513-628) nos dice que este sitio se localiza a $13 \mathrm{kms}$. al norte de la ciudad de Chetumal a orillas de la bahía. Se componía, al parecer, de unas 18 estructuras rodeadas por una muralla de $300 \mathrm{mts}$. de largo hacia el lado norte, $770 \mathrm{mts}$. hacia el oeste y 400 hacia el sur; abarcaba aproximadamente unas 27 has. La disposición del sitio, lo mismo que la muralla, recuerdan, en cierta forma, a Tulum ya que está también rodeada al norte, oeste y sur por una muralla y tiene al mar por el oeste (Fig. 4). Webster (1967:361-371) hace notar entre otras cosas que los edificios del sitio no son tan impresionantes como los de Tulum, y que la labor constructiva se dirigió fundamentalmente a la construcción de la muralla, ya que fue construida con piedra a junta seca, apilada hasta una altura promedio de $3 \mathrm{mts}$. con un espesor de 4 a $5 \mathrm{mts}$. y la fecha de su construcción corresponde a la época de Tulum.

En la costa de Quintana Roo existen ejemplos de sitios amurallados que reflejan una situación de guerra e inestabilidad. Casi con 
seguridad se puede decir que todas estas ciudades amuralladas fueron construidas cuando Mayapán era el centro de dominio, desintegrándose posteriormente y formando una gran cantidad de ciudades descentralizadas, situación que se refleja en la costa oriental. Algunas de estas ciudades amuralladas, al parecer, se construyeron para protegerse de gente que venía del mar; otras en cambio dan la idea de que eran puertos a donde podían llegar a acogerse, y a su vez estaban protegidos contra ataques del exterior.

El sistema económico de la costa oriental, reinante durante este periodo, se podría caracterizar como redistributivo, en donde una de las características principales de la economía es el intercambio de bienes. En este caso todo parece indicar que el grupo en el poder recibía la mayor parte del excedente de la producción, y a su vez redistribuía la mayor parte de estos productos entre diversos segmentos de la población. Todo parece indicar que estamos ante una organización transitoria del Señorío al Estado, al asumir la existencia de un mercado, la creación de un sistema de rentas, la posible existencia de una burocracia y un ejército. En este sentido el ejército no era el único grupo que se beneficiaba con la provisión, pues tanto la corte como la burocracia y el grupo religioso eran mantenidos con los excedentes estatales.

Lamentablemente no es posible, por ahora, llevar a cabo un estudio exhaustivo sobre todos estos aspectos políticos, económicos y sociales; los datos son incompletos y con frecuencia contradictorios. Es muy probable que haya datos disponibles en los archivos; no en las obras de los cronistas más ambiciosos, que describen la cultura en su conjunto, sino más bien en registros y relaciones locales.

Las evidencias arqueológicas indican que los contactos entre la costa y el resto de la zona maya eran comunes durante este periodo, y que la costa orieintal de Quintana Roo era una de las vías de comunicación más usadas. En consecuencia algunos sitios necesitaron ser reforzados con murallas, como por ejemplo Xcaret, Xelhá, Tulum e Ichpaantúm, entre otros.

\section{Comentario general}

Sobre el militarismo en al zona maya existen ya bastantes trabajos que señalan fortificaciones; para Quintana Roo las noticias se encuentran un poco desperdigadas en artículos, libros de diferentes fechas y en informes de exploraciones. En la actualidad el Centro 
Regional del Sureste INAH ha realizado varios proyectos arqueológicos en la región, permitiéndose con ello un conocimiento más pro fundo de la situación prevaleciente durante la etapa inmediatamente anterior a la conquista. El proyecto arqueológico de Tulum es uno de ellos, por tal motivo me ha interesado el problema del militarismo en la costa de Quintana Roo. Hemos explorado parte de la muralla de Tulum, he visitado la mayoría de los sitios que presentan este tipo de defensa y además he tomado en consideración algunos planteamientos interesantes hechos por Thompson y otros autores.

Tulum puede ser un ejemplo interesante para el estudio de una de las etapas propuestas en el modelo de evolución social y cultural de Piña Chán, ya que presenta, por una parte, muchos elementos religiosos asociados a la guerra y elementos netamente militaristas.

Aunque el proyecto ha sido planteado considerando varias posibilidades, básicamente partimos de dos hipótesis: una sostenida con anterioridad por varios integrantes del Centro Regional del Sureste (INAH) indicando que Tancah y Tulum son un solo sitio y que el segundo se deriva del primero. Tancah ha sido un sitio estudiado en varias ocasiones; por tal motivo hoy se conoce bastante bien su cronología, siendo este un sitio bastante más antiguo que Tulum. La idea nace al parecer de un reconocimiento preliminar en el lado norte de Tulum observándose desde entonces una continuidad con Tancah y por tal motivo se habla de un solo asentamiento (Benavides 1981).

Otra es la de Eric Thompson que plantea la posibilidad de que pobladores de Tulum fueran del grupo chontal o putun. Como sabemos este grupo era eminentemente comercial, por tal motivo no es nada dudoso que pretendieran dominar la ruta comercial marítima de toda la costa, teniendo en Tulum y otros sitios guarniciones.

Tomando en consideración estas y otras posibilidades hemos tratado de analizar someramente las fortificaciones que hemos visitado $\mathrm{y}$ hemos notado algunas diferencias entre las murallas de los distintos sitios, por ejemplo las murallas de Xelhá y Xcaret son murallas construidas a orillas de la caleta, dando la idea de que se hicieron para defenderse de gente que llega del mar, mientras que en Tulum e Ichpaatum son murallas que sirven para protegerse de la gente del interior, están abiertas hacia el mar.

En otros casos existe una muralla que rodea a los edificios principales, como protegiendo a la élite, que debió vivir en esas partes. Aunque falta todavía mucho por investigar, la mayor ocupación 
en la costa oriental corresponde precisamente al momento inmediatamente anterior a la Conquista (1200-1250 d.C.), muchos son los asentamientos que se localizan a lo largo de la costa y en el interior adyacente mostrando claras evidencias de una densa población, existen abundantes y variados recursos marinos que se pueden explotar a través del año, además de la proximidad a la ruta marítima del caribe.

El patrón de asentamiento durante la Época Prehispánica varió considerablemente; al principio predominaron los asentamientos alrededor de los lagos y orillas del mar, caracterizándose por ser sociedades de agricultores incipientes y pescadores; posteriormente cambia el patrón de asentamiento y se localizan sitios muy grandes. En este caso, se trata de centros "teocráticos" con grandes plataformas, basamentos piramidales, templos, palacios y edificios públicos; al parecer la religión dominaba, eran guiados por sus dioses y sacerdotes, logrando así una época de esplendor hasta entonces sin precedentes; Cobá es el caso típico de un centro teocrático en Quintana Roo: es una gran ciudad abierta, sin defensas aparentes, aunque existen estelas en donde por las representaciones podría deducirse que existía una estratificación y aún en otras se podría pensar en prisioneros, como es caso de las estelas 1 y 20 donde el personaje principal está parado sobre dos sujetos encogidos con la cabeza hacia abajo y los brazos atados. A ambos lados se ven personajes arrodillados y con los brazos amarrados (Fig. 5).

Con los datos presentados someramente, se puede ver en términos generales que existe un desarrollo sociocultural ya que se han reportado sitios de cazadores y pescadores (Conchero de Can Cun, Cochol $\mathrm{Na}$, etc.), sitios con sociedades teocráticas (por ejemplo Cobá, nombro sólo uno por ser tal vez el más representativo) y sociedades gobernadas por una casta militar.

Las evidencias arqueológicas nos permiten pensar que las relaciones entre los individuos en épocas tempranas de la evolución de la sociedad eran de carácter comunal, es decir, que la mayoría de la población se dedicaba a la producción de alimentos, con un acceso igualitario a los bienes y servicios.

Posteriormente el desarrollo de grupos ya sean religiosos, artesanales, comerciantes, etc., que no participaban directamente en la obtención de alimentos se distribuyó de una manera determinada en el espacio y son los que gobiernan por muchos años, auxiliados por una incipiente "policía". 
Más tarde, a finales del Horizonte Clásico, una gran crisis se da en Mesoamérica y en "medio del caos se incuba un mundo nuevo" y los guerreros se convierten en la clase dominante y se dan los estados militaristas en diversos grados de desarrollo.

\section{BIBLIOGRAFIA}

ANDREws IV, F. W. y A. P. AndRews

1975 "A Preliminary Study of the Ruins of Xcaret, Quintana Roo, México". Middle American Research Institute, Tulane University, Pub. 40, New Orleans.

Andrews, George

1975 Maya Cities: Placemaking and Urbanization. Norman, University of Oklahoma, Col.

BARrera Rubio, Alfredo

1977 "Exploraciones Arqueológicas en Tulum Quintana Roo". Boletín de la Escuela de Ciencias Antropológicas de la Universidad de Yucatán. Mayo-Junio, año 4, No. 24:23-63, Mérida.

Benavides C., Antonio

1981 "Ecab: panorama general de una provincia del siglo XVI en Yucatán". Memoria del Congreso Interno 1979. Centro Regional del Sureste. INAH. México.

Benavides C., Antonio y A. Andrews

1979 "Ecab: poblado y Provincia del siglo XVI en Yucatán". Cuadernos de los Centros Regionales. Centro Regional del Sureste SEP. INAH. México.

CARneiro, Robert L.

1970 "A Theory of the origin of the State", Science, vol. 169: 733738, U.S.A.

Chamberlain, Robert S.

1974 Conquisía y Colonización de Yucatán, 1517-1550. Introd. J. I. Rubio Mañé, Porrúa, México.

Escalona Ramos, Alberto

1946 "Algunas ruinas prehistóricas en Quintana Roo". Boletín de la Sociedad Mexicana de Geografía y Estadística, Tomo LXI, No. 3, México.

Follete, Prescott, H. F.

1932 "War and Weapons of the Maya", Middle American Papers, Middle American Research Institute, Pub. 4 New Orleans.

González de la Mata, R. y Trejo, A. F.

1981 "Playa del Carmen: excavaciones en la costa oriental de Quintana Roo", Memorias del Congreso Interno 1979, Centro Regional del Sureste, pp. 123-138, SEP, INAH, México.

JimÉnez MoReno, WigBerto

1976 "Síntesis de la Historia pretolteca de Mesoamérica" Esplendor del México Antiguo, 1019-1108 Serie de Investigaciones Antropológicas de México, México.

KurJack, EdWard B. y F. WyLlys Andrews V.

1976 "Early boundary maintenance in northwest Yucatan, México", American Antiquity, 41:318-325, Washington. 
Landa, Diego de

1966 Relación de las cosas de Yucatán, 9a. ed., introd. Angel María Garibay, Porrúa, México.

LOTHROP, S. K.

1924 Tulum, an Archaeological Study of the East Coast of Yucatan, Carnegie Institution of Washingotn, Publ. 335, Washington, D.C.

OchoA L. y E. VARGAS

1979 "El colapso maya, los chontales y Xicalango". Estudios de Cultura Maya, Vol. XII, pp. 111-156, Centro de Estudios Mayas, UNAM, México.

Palerm, Ángel.

1956 "Notas sobre las construcciones militares y la guerra en $\mathrm{Me}-$ soamérica", Anales del INAH, Tomo VIII, No. 37, México.

Piña Ghán, Román

1976 "Un modelo de evolución social y cultural del México precolombino", en Serie Arqueología, Departamento de Monumentos Prehispánicos, INAH, México.

Relaciones de Yucatán

1898-1900 Pról. de José María Asensio, 2 vols., Real Academia de la Historia, Madrid (Col. de documentos inéditos relativos al descubrimiento, conquista y organización de las antiguas posesiones españolas de Ultramar, Segunda Serie, Núms. 11 y 13).

Repeto Tio, Beatriz E.

1979 "Desarrollo Militar de los Mayas Prehispánicos", Tesis, Universidad de Yucatán, Mérida, Yucatán.

Roys, RaLPH L.

1957 The Political Geography of the Yucatan Maya, Carnegie Institution of Washington, Pub. 613, Washington, D.C.

Robles, Fernando

1981 "Xelhá: un proyecto de investigación", Memorias del Congreso Interno 1979, Centro Regional del Sureste, pp. 101-121.

Ruz Lhuillier, Alberto

1951 "Chichén Itzá y Palenque, ciudades fortificadas", Homenaje a Alfonso Caso, pp. 331-342, México, Imprenta Nuevo Mundo.

SANDERS, WILliam T.

1955 "An Archaeological Reconnaissance of Northern Quintana Roo". Current Reports, No. 24, Carnegie Institution of Washington

SERVice, E. R. Department of Archaeology.

1975 Origins of the state and civilization. The procces of cultural evolution, New York, W. W Norton.

SHook, EDWIN M.

1952 "The Great Wall of Mayapan", Current Reports, Vol. I; No. 2: 7-35, Carnegie Institution of Washington, Department of Archaeology, Cambridge, Mass.

Stephens, J. L.

1843 Incidents of travel in Yucatan, Harpere Brothers (2 vols.), New York.

Thompson, J. ERIC

1948 "Pitfalls and stimuli in the interpretation of history through loan Words", Philological and Documentary Studies, Vol. I, Middle American Research Institute, Pub. 11, New Orleans. 
1959 Grandeza y Decadencia de los Mayas, Trad. de Lauro José Zavala, Fondo de Cultura Económica, México.

Webster, David, L.

1976 "Defensive Earthworks at Becan, Campeche, Méxco", Middle American Research Institute, Tulane University, Pub. 41, New Orleans.

1979 "Cuca, Chacchob, Dzonot Ake, Three Walled Northern Maya Centers", Ocasional Papers in Anthropology, The Pennsylvania State University, University Park, No. 11, Pennsylvania.

Vargas Pagheco, Ernesto

$\mathrm{s} / \mathrm{f} \quad$ La ciudad Militarista de Teotenango, en prensa.

s/fa "Apuntes para el análisis del Patrón de asentamiento en Tulum", Manuscrito.

VICEK, DAVID

1978 "Muros de delimitación en Chunchucmil", Boletín de la Escuela de Ciencias Antropológicas de la Universidad de Yucatán, Año 5, No. 28: 55-62, Mérida, Yucatán. 

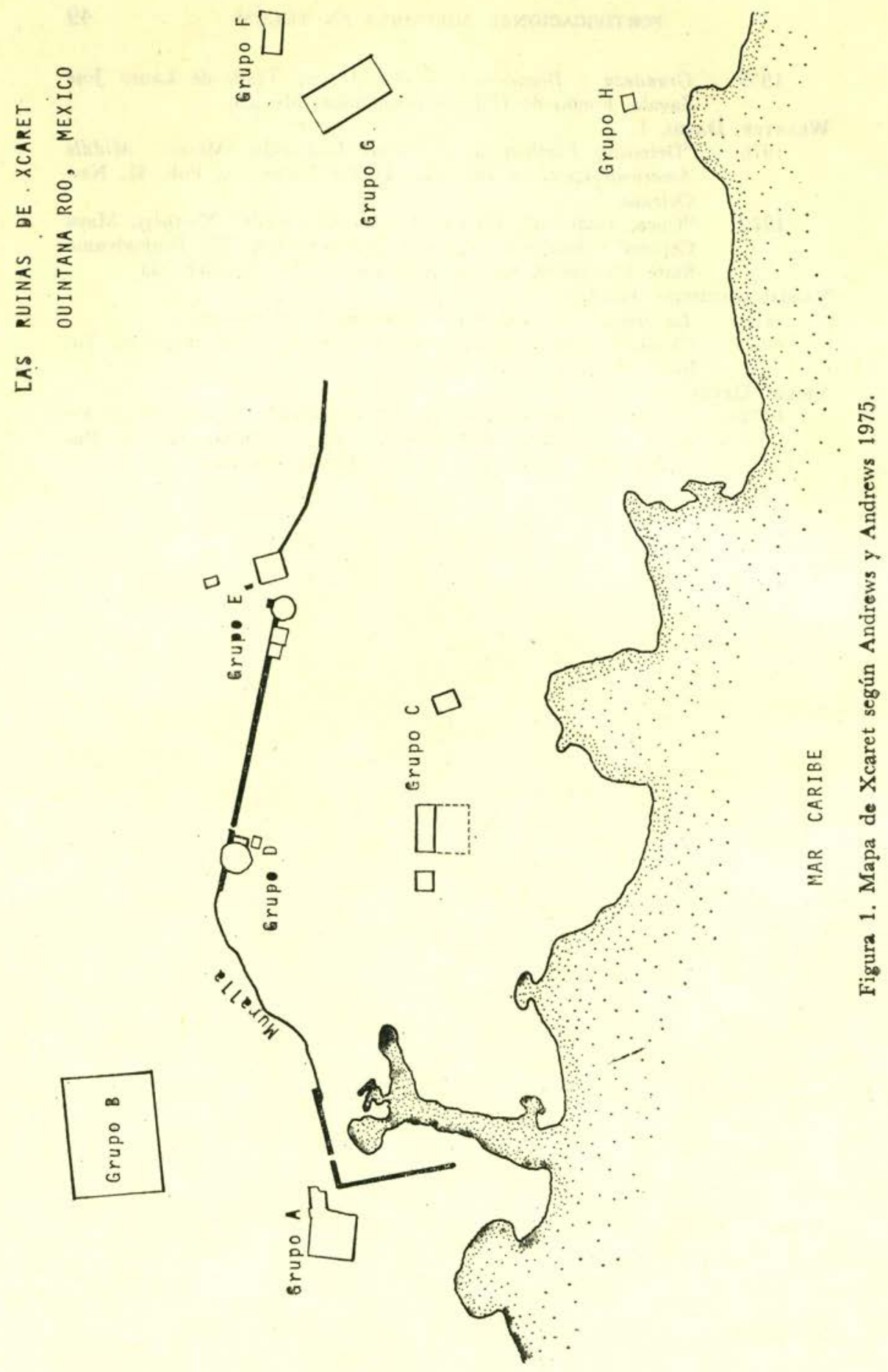

Estudios de Cultura Maya. Vol. XV, 1984

Instituto de Investigaciones Filológicas/

Centro de Estudios Mayas, UNAM

http://www.iifilologicas.unam.mx/estculmaya/ 


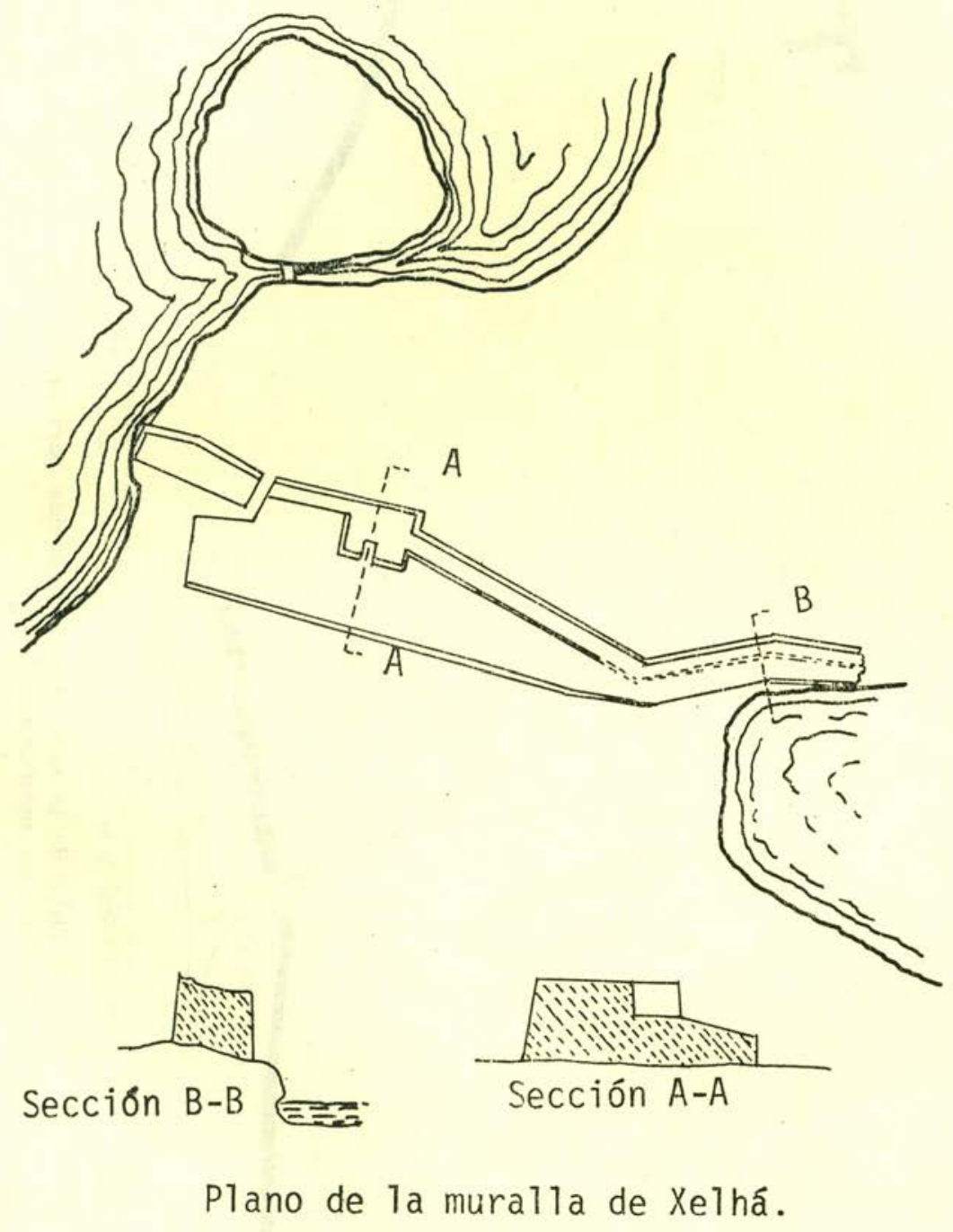

Figura 2. Plano de la muralla de Xelhá según Lothrop 1924. 


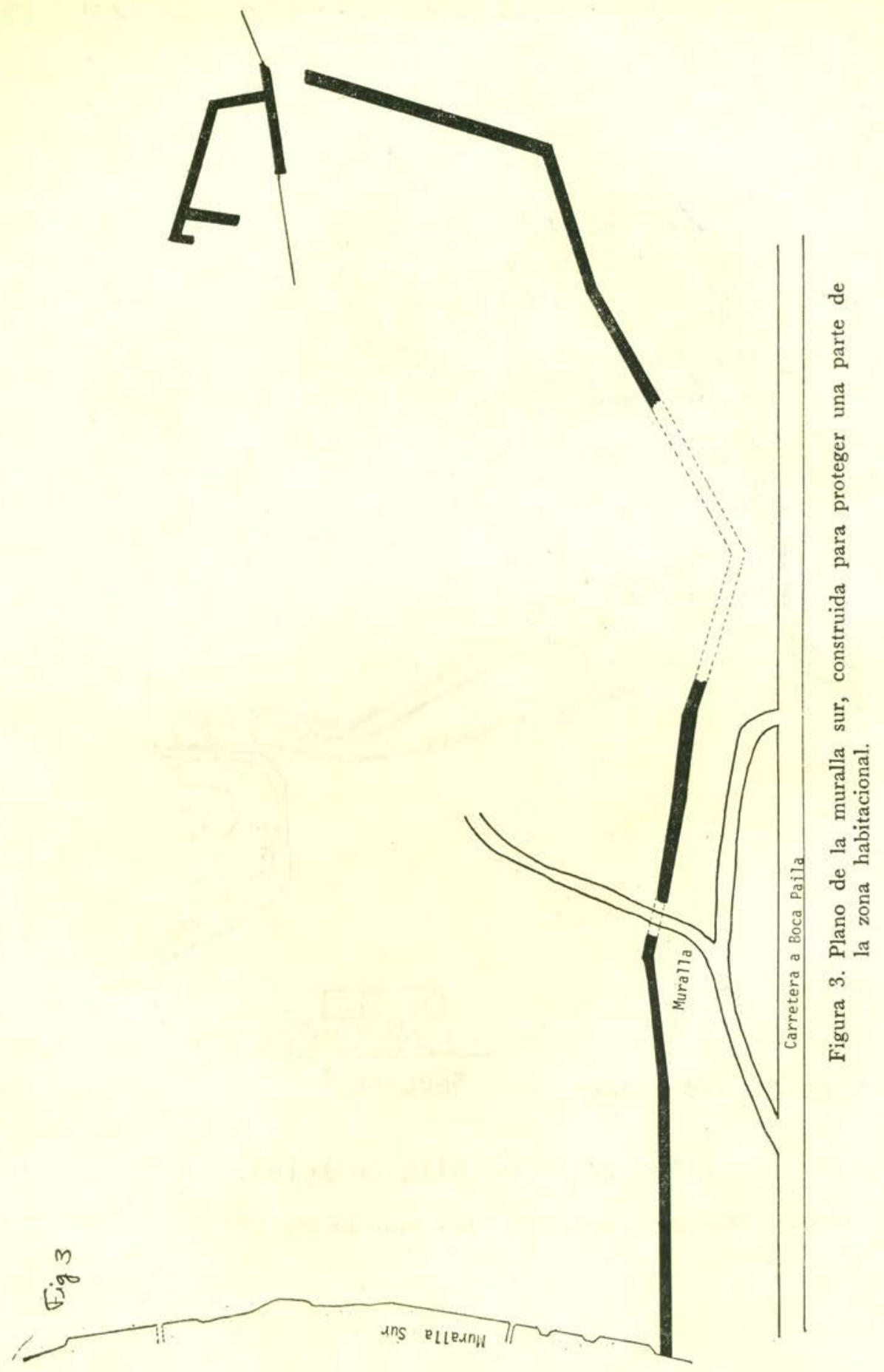

Estudios de Cultura Maya. Vol. XV, 1984

Instituto de Investigaciones Filológicas/

Centro de Estudios Mayas, UNAM

http://www.iifilologicas.unam.mx/estculmaya/ 


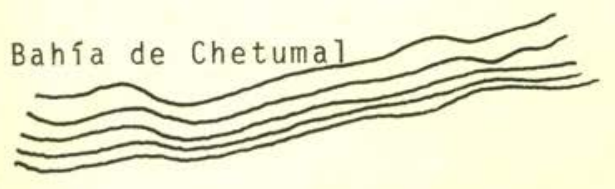

$\infty$ Estela

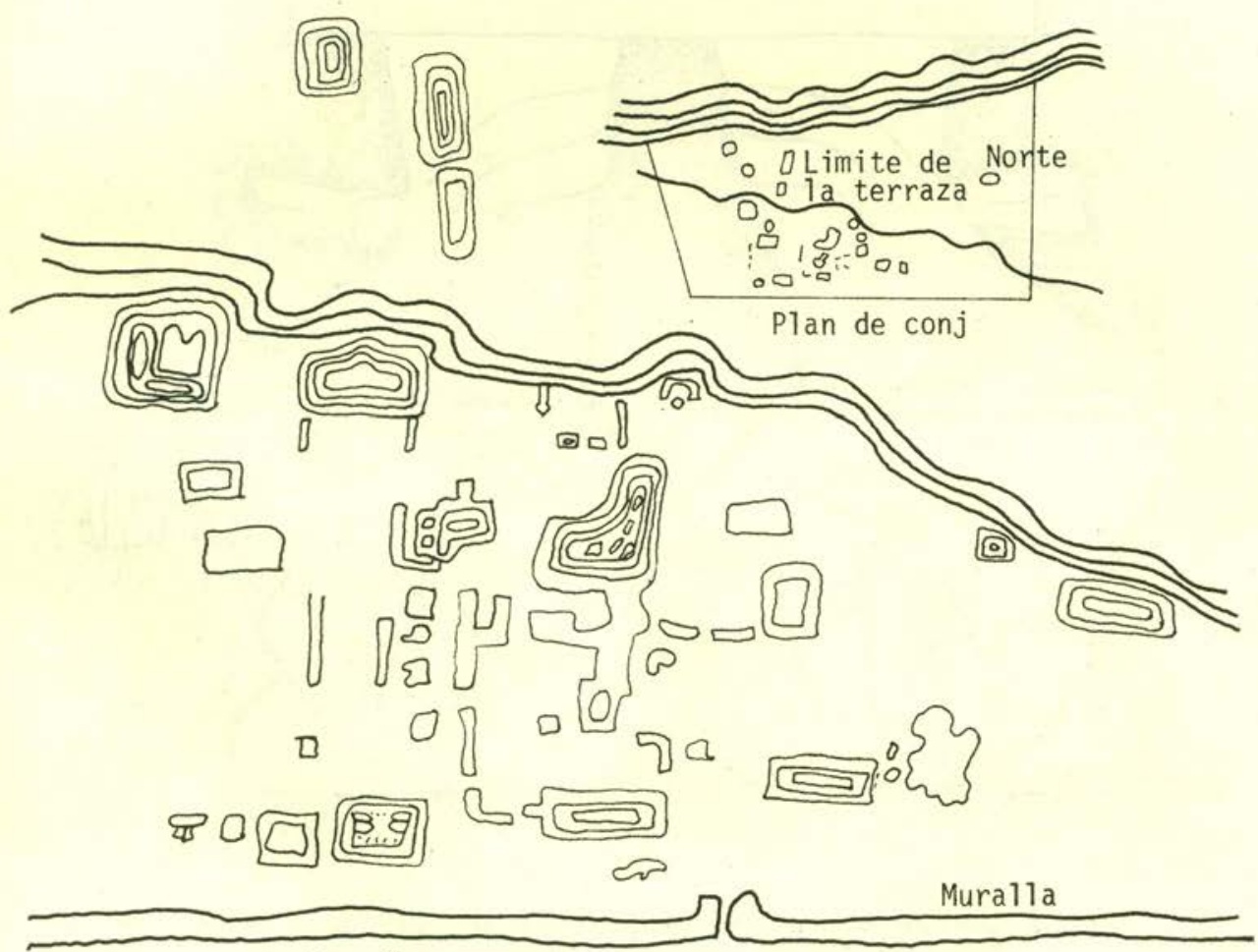

Muralla

Figura 4. Plano de Ichpaantun tomado de Lizardi Ramos 1946. 


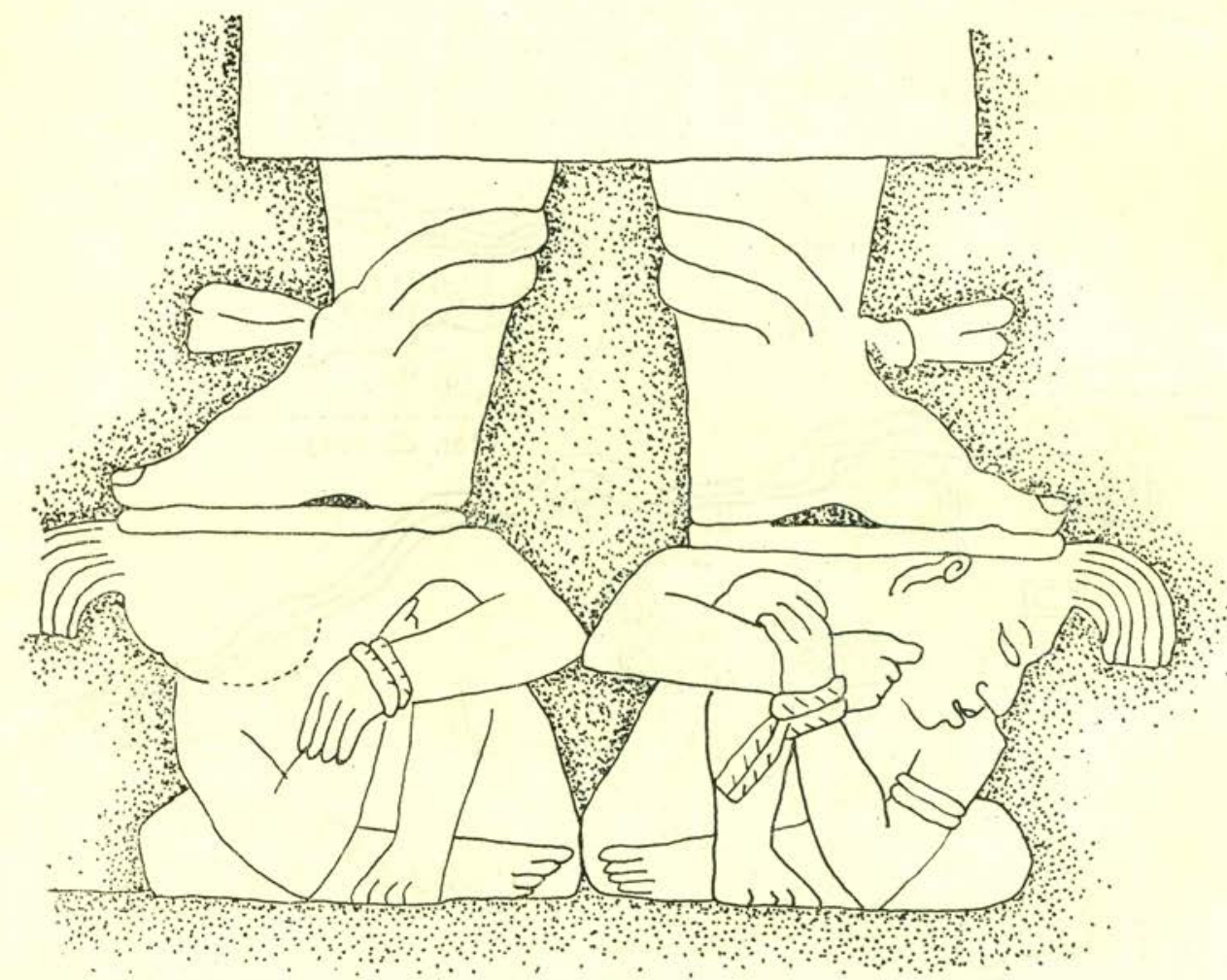

Figura 5. Cautivos bajo los pies del personaje principal de la estela 1 de Cobá, tomado de Thompson (1932). 


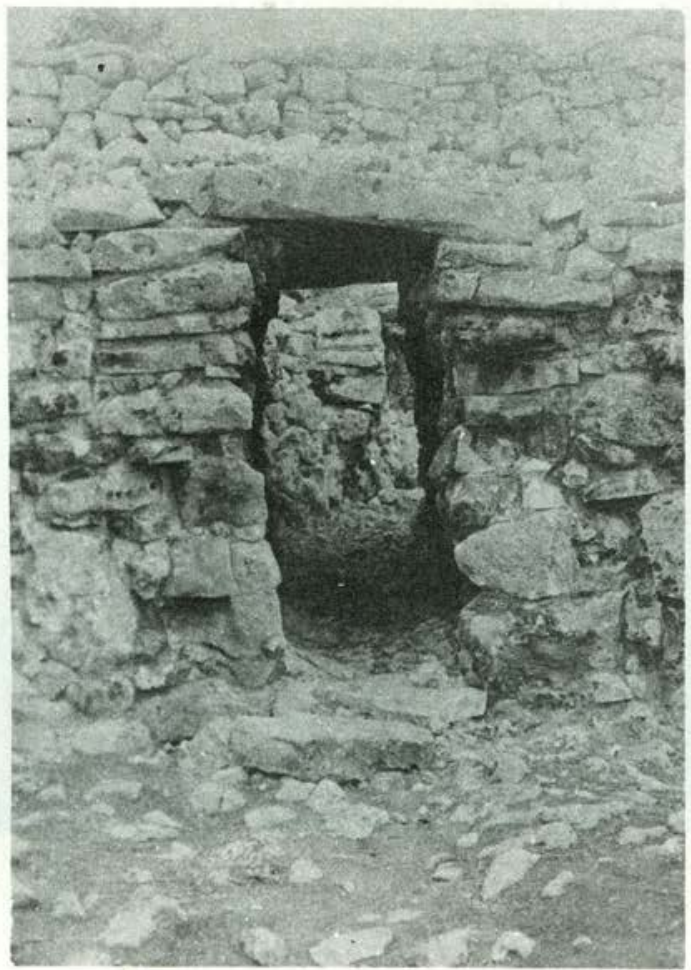

Lámina 1. Puerta noreste de la muralla de Tulum.

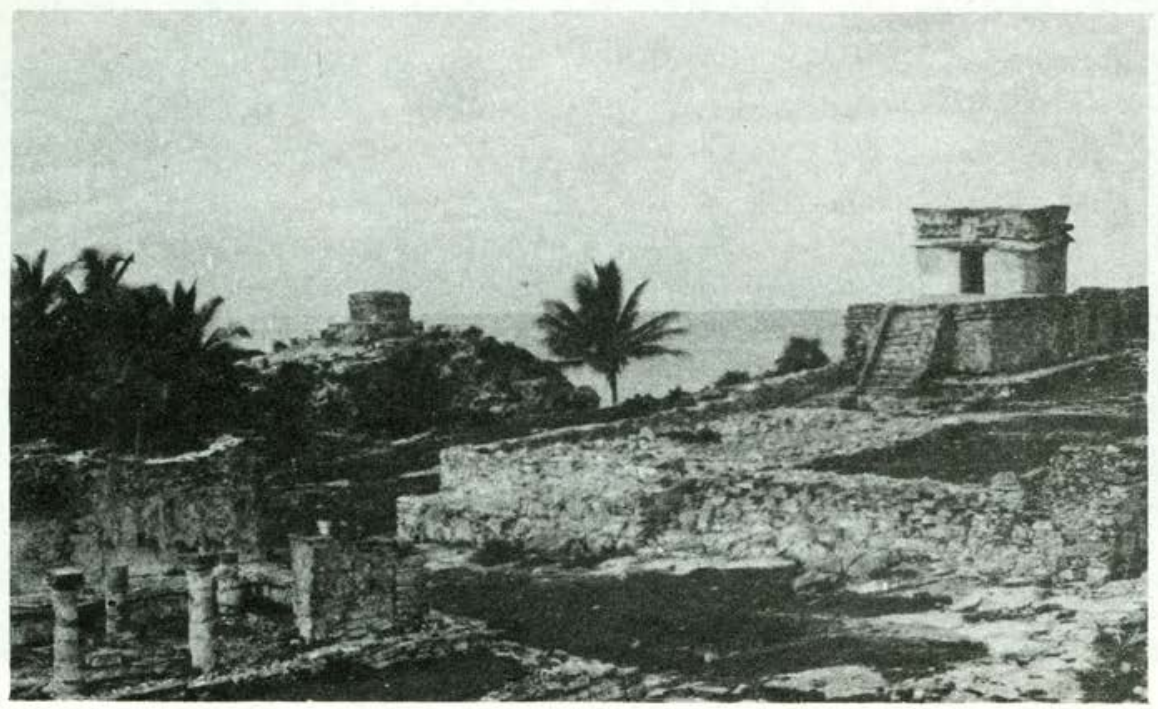

Lámina 2. Muralla del recinto interior.

Estudios de Cultura Maya. Vol. XV, 1984

Instituto de Investigaciones Filológicas/

Centro de Estudios Mayas, UNAM

http://www.iifilologicas.unam.mx/estculmaya/ 


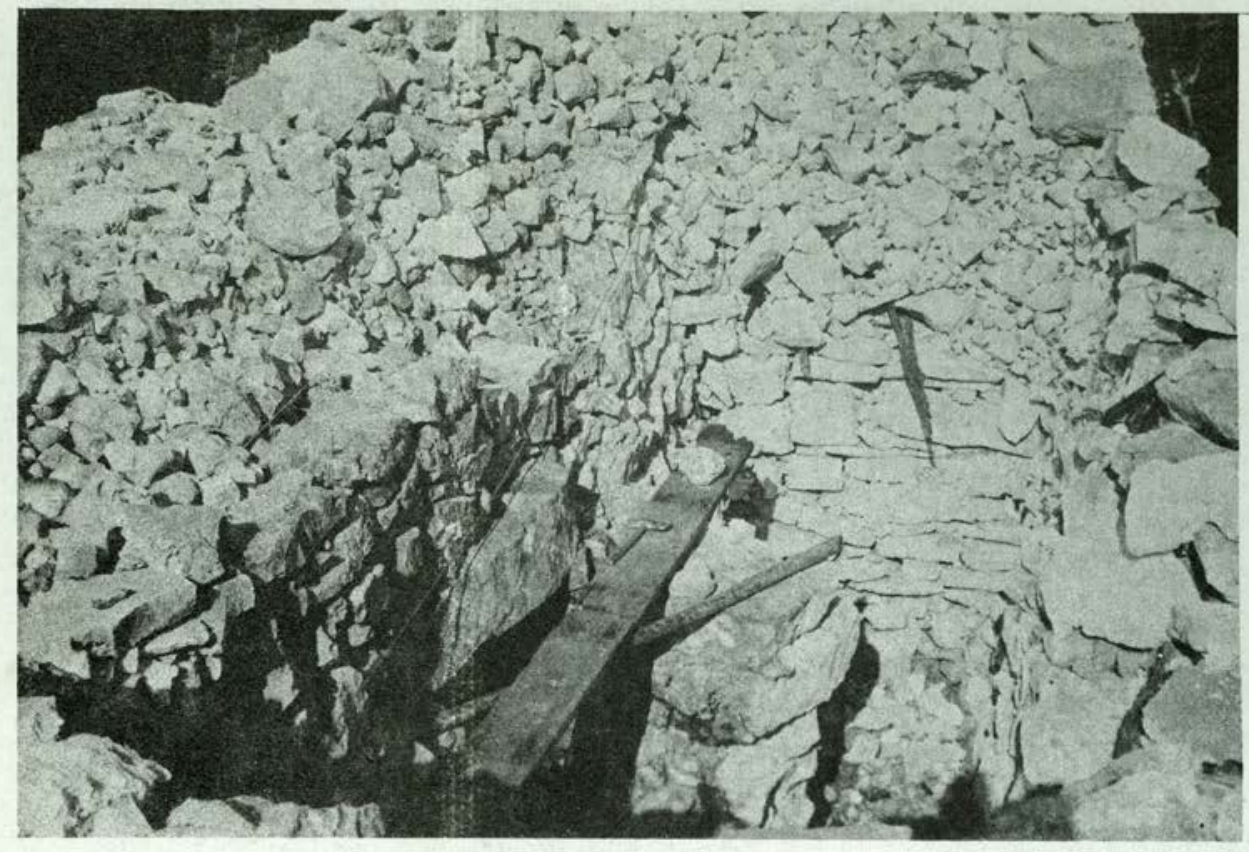

Lámina 3. Pequeño cuarto dentro de la muralla, lado norte.

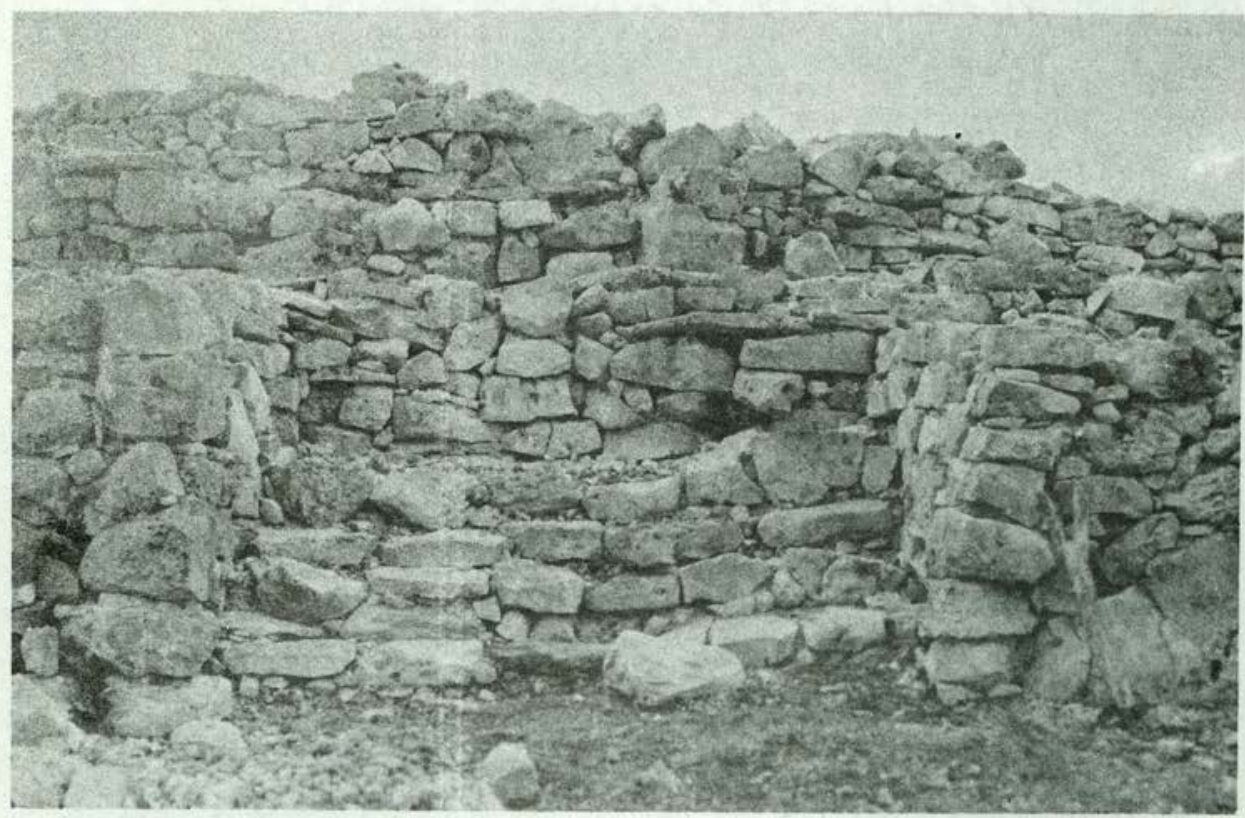

Lámina 4. Escalera que servía de acceso para llegar a la parte superior de la muralla. 